\title{
Analisis Disiplin Pengelolaan Keuangan Usaha Mikro dan Kecil Kabupaten Pohuwato Provinsi Gorontalo
}

\author{
Muhammad Anas ${ }^{1}$ \\ Jurusan Manajemen, STIE Ichsan Pohuwato \\ e-mail: muh.annas74@yahoo.com \\ Sulaiman ${ }^{2}$ \\ Jurusan Manajemen, STIE Ichsan Pohuwato
}

\begin{abstract}
ABSTRAK
The aim of this research is to analysis the financial management discipline of micro and small enterprises at Pohuwato region. Gorontalo Province. The length aim of this research is the best practice for the micro and small enterprises. The method of this research is used quantitative research. while collecting data is used observation and questionnaire by applying multiple regression. The result of this research shows that the competencies of the enterprises and commitment of financial management for the enterprises having a positive influence towards the discipline of financial management for micro and small enterprises at Pohuwato Region, Gorontalo Province. this case is shown by statistical analysis, where the enterprises' competencies in partial shows that the t calculation is bigger than t table or $6.549>1.968$; While, the financial commitment also having a positive and significant influence; this case can be shown by $t$ calculation is bigger than T table, or $4.035>1.968$. Simultaneously, both independent variables (enterprises' competencies and financial management commitment also having positive and significance influences towards financial management of micro and small enterprises towards financial management of micro and small enterprises. this case can be shown by $F$ calculation is bigger than $F$ table. This case can be interpreted that micro and small enterprise is having a good of awareness, for learning a discipline of a good financial management; the other side that micro and small enterprises having a high financial commitment for developing their enterprises in the future.
\end{abstract}

\section{Keywords: Discipline of Financial Management, entrepreneur competence and financial commitment of Micro and Small Busine}

\begin{abstract}
The aim of this research is to analysis the financial management discipline of micro and small enterprises at Pohuwato region. Gorontalo Province. The length aim of this research is the best practice for the micro and small enterprises. The method of this research is used quantitative research. while collecting data is used observation and questionnaire by applying multiple regression. The result of this research shows that the competencies of the enterprises and commitment of financial management for the enterprises having a positive influence towards the discipline of financial management for micro and small enterprises at Pohuwato Region, Gorontalo Province. this case is shown by statistical analysis, where the enterprises' competencies in partial shows that the $t$ calculation is bigger than t table or $6.549>1.968$; While, the financial commitment also having a positive and significant influence; this case can be shown by $t$ calculation is bigger than $T$ table, or $4.035>1.968$. Simultaneously, both independent variables (enterprises' competencies and financial management commitment also having positive and significance influences towards financial management of micro and small enterprises towards financial management of micro and small enterprises. this case can be shown by $F$ calculation is bigger than $F$ table. This case can be interpreted that micro and small enterprise is having a good of awareness, for learning a discipline of a good financial management; the other side that micro and small enterprises having a high financial commitment for developing their enterprises in the future.
\end{abstract}

Keywords: Discipline of Financial Management, entrepreneur competence and financial commitment of Micro and Small Busine

Jurnal Frontiers Vol 1 No 2, Agustus 2018

P-ISSN: 2621-0991 E-ISSN: 2621-1009 


\section{PENDAHULUAN}

Usaha Mikro dan Kecil memiliki peranan penting dalam perekonomian di Indonesia dan merupakan salah satu prioritas dalam pembangunan ekonomi nasional. Hal ini selain karena usaha tersebut merupakan tulang punggung sistem ekonomi kerakyatan yang tidak hanya ditujukan untuk mengurangi masalah kesenjangan antar golongan pendapatan dan antar pelaku usaha, ataupun pengentasan kemiskinan dan penyerapan tenaga kerja. Lebih dari itu, pengembangannya mampu memperluas basis ekonomi dan dapat memberikan konstribusi yang signifikan dalam mempercepat perubahan struktural, yaitu meningkatnya perekonomian daerah dan ketahanan ekonomi nasional.

Pada umumnya permasalahan yang dihadapi oleh usaha mikro dan kecil berkaitan dengan masalah kemampuan manajemen atau pengelolaan yang kurang profesional. Hal ini disebabkan pengetahuan yang dimiliki sangat terbatas. Dengan belajar dari pengalaman pada beberapa dasa warsa terakhir yang telah melahirkan perekonomian yang kurang sehat, maka kebijakan pembangunan di era reformasi ini dilakukan dengan keberpihakan pada ekonomi rakyat (sistim ekonomi kerakyatan) melalui salah satu programnya pemberdayaan Usaha Mikro Kecil yang merupakan wujud kehidupan ekonomi rakyat Indonesia.

Berdasarkan data dari BPS Kabupaten Pohuwato tahun 2015 jumlah usaha mikro dan kecil sebanyak 2588 yang tersebar di 13 kecamatan yang ada di Kabupaten Pohuwato, hal ini mengalami pertumbuhan setiap tahunnya, namun demikian bukan berarti bahwa para pelaku usaha mikro dn kecil di daerah ini telah memiliki kompetensi yang bagus dalam menjalankan usahanya disebabkan karena ada yang memulai usahanya karena faktor sekedar ingin mencoba bahkan ada yang memulai usahanya karena melihat tetangganya memiliki usaha yang cukup laris, dan hal ini berarti bahwa mereka tidak memiliki pengetahuan yang cukup dalam membagun usaha yang sudah pasti mereka tidak disiplin dalam pengelolaan modalnya seperti tidak memisahkan keuangan pribadi dan keuangan usaha dan penggunaan modalnya tidak sesuai dengan peruntukkannya.

Dengan demikian tim peneliti memandang urgent, untuk melakukan penelitian dengan mengkaji Disiplin Pengelolaan Keuangan (Survei Usaha Mikro dan Kecil di Kabupaten Pohuwato Provinsi Gorontalo)".

1. Bagaimana disiplin pengelolaan keuangan Usaha Mikro dan Kecil di Kabupaten Pohuwato Provinsi Gorontalo?

2. Apakah kompetensi pengusaha dan komitmen keuangan mempunyai pengaruh secara parsial maupun simultan terhadap disiplin pengelolaan keuangan Usaha Mikro dan Kecil di Kabupaten Pohuwato Provinsi Gorontalo ?

Penelitian ini diharapkan mampu memberikan manfaat dan masukan bagi berbagai pihak yang berkepentingan. manfaat dari penelitian ini yaitu:

1. Sebagai bahan informasi bagi Usaha Mikro dan Kecil untuk meningkatkan disiplin pengelolaan keuangan dalam menjalankan usahanya.

2. Sebagai bahan referensi dan acuan bagi pihak akademisi terkait dengan mata kuliah ekonomi pada umumnya dan khususnya mata kuliah keuangan dan kewirausahaan.

Mengelola keuangan dimulai dari perencanaan keuangan, pelaksanaan hingga melakukan evaluasi. Indriani et.al (2009) mendefinisikan rencana keuangan 
sebagai suatu strategi yang apabila dijalankan bisa membantu mencapai tujuan keuangan di masa datang. Tujuan keuangan selain menambah kekayaan juga menjaga agar kehidupan keuangan tidak kacau akibat segala sesuatu yang tidak diinginkan seperti kematian, kecelakaan, turunnya nilai asset seperti saham, properti dan lain lain.

Menurut Senduk (2000), dalam mengatur keuangan tidak berarti harus hemat, tetapi yang paling penting adalah mengetahui jumlah yang pantas untuk setiap pos pengeluaran dan berusaha memenuhi jumlah tersebut. Ada orang yang hanya fokus kepada bagaimana mendapatkan penghasilan, akan tetapi tidak pernah memikirkan bagaimana mengatur pengeluaran sehingga tidak bisa membedakan antara keinginan (want) atau kebutuhan (need). Disisi lain, seseorang yang penghasilannya tidak seberapa, tetapi dapat hidup berkecukupan. Golongan ini tidak pernah mengeluh dan bisa menekan pos-pos pengeluaran sehingga tetap rendah karena menyadari bahwa penghasilannya terbatas, sehingga lebih memfokuskan pada pengaturan keuangan.

Syamsu Alam (2005) dalam penelitiannya yang berjudul faktor-faktor yang mempengaruhi kinerja usaha sektor informal di Sulawesi Selatan mengemukakan bahwa dilihat dari aspek manajemen keuangan, pada umumnya usaha sektor informal belum melakukan pemisahan keuangan, antara uang untuk usaha dengan uang untuk konsumsi keluarga, dan hal ini menyulitkan perkembangan usahanya, sedangkan pembukuan sudah dilakukan walaupun masih sangat sederhana, demikian juga dengan rencana keuangan, usaha sektor informal melakukannya walaupun sangat sederhana.

Kompetensi sebagai kemampuan seseorang untuk menghasilkan pada tingkat yang memuaskan di tempat kerja, termasuk diantaranya kemampuan seseorang untuk mentransfer dan mengaplikasikan keterampilan dan pengetahuan tersebut dalam situasi yang baru dan meningkatkan manfaat yang disepakati. Suswardji dkk (2012).

Selanjutnya kompetensi menurut Sanchez Jose (2011) adalah "un underlying characteristic of an individual that is casually realated to cretarionreferenced effective and/or superior performance in a job or situation" atau karakteristik dasar seseorang (individu) yang mempengaruhi cara berpikir dan bertindak membuat generalisasi terhadap segala situasi yang dihadapi serta bertahan cukup aman dalam diri manusia.

Raduan, (2006), melakukan penelitian yang berjudul, "The dynamics of entrepreneurs' success factors in influencing venture growth", Penelitian ini menemukan hubungan yang signifikan antara pertumbuhan usaha dan pengusaha dengan inisiatif pribadi yang tinggi, fokus pada bidang kompetensi tertentu dalam operasi, keuangan, pemasaran dan sumber daya manusia.

Karakteristik wirausaha yang sukses menurut Zimmerer dan Scarbrough (1996) dalam Alma (2013) adalah memiliki komitmen yang tinggi terhadap tugasnya, mau bertanggung jawab, mempertahankan internal locus of control, peluang untuk mencapai obsesi, memiliki keahlian dan keterampilan khusus, toleransi menghadapi kebimbangan dan ketidakpastian, yakin pada dirinya, bersikap jujur, kreatif dan fleksibel, ingin memperoleh balikan segera, enerjik tinggi, motivasi untuk lebih unggul, berorientasi ke masa depan, mau belajar dari kegagalan, dan mampu memimpin.

Sarwoko (2013), melakukan penelitian dengan judul, "Entrepreneurial 
Characteristics and Competency as Determinants of Business Performance in SMEs",di mana hasil penelitiannya menggambarkan bahwa kompetensi kewirausahaan memberikan peran kinerja bisnis, bahwa semakin tinggi kompetensi pemilik usaha kecil dan menengah akan menyebabkan kinerja bisnis yang lebih tinggi, seperti untuk tinggi rendahnya kompetensi ditentukan oleh karakteristik pengusaha.

Para pengusaha harus memiliki komitmen keuangan untuk melaksanakan disiplin pengelolaan keuangan Usaha Mikro dan Kecil untuk mengelola perusahaan dalam cara yang tepat. Rakhman, (2011) dalam penelitiannya menemukan bahwa komitmen pengusaha sangat penting untuk mendorong terciptanya kekuatan bisnis baru karena mampu mengakumulasi modal karena memiliki pertumbuhan yang berkelanjutan.

Porter dalam Suryana (2013), mendefinisikan komitmen sebagai kekuatan yang bersifat relatif dari individu dalam mengidentifikansikan keterlibatan dirinya. Hal ini dapat ditandai dengan tiga hal yaitu: penerimaan terhadap nilainilai dan tujuan organisasi, kesiapan dan kesediaan untuk berusaha sungguhsungguh atas nama organisasi, dan keinginan untuk mempertahankan usahanya.

Richard dalam Suryana (2013) mendefinisikan komitmen sebagai rasa identifikasi (kepercayaan terhadap nilainilai), keterlibatan (kesediaan untuk berusaha sebaik mungkin demi kepentingan perusahaan dan loyalitas yang dinyatakan oleh seorang wirausaha terhadap perusahaannya. Coleman (2007) menekankan akses ke pinjaman dan sangat penting untuk modal keuangan untuk mendukung kinerja perusahaan.

\section{METODE}

Penelitian ini dilaksanakan di Kabupaten Pohuwato Provinsi Gorontalo dengan pertimbangan berdasarkan survei awal bahwa pertumbuhan Usaha Mikro dan Kecil di Kabupaten ini mengalami peningkatan yang cukup pesat setiap tahunnya sehingga peneliti tertarik untuk menganalisis tingkat disiplin pengelolaan keuangan Usaha Mikro dan Kecil di kabupaten Pohuwato.

Pengambilan jumlah sampel pada penelitian ini mengacu pada pendapat Roscoe (1975) dalam Uma Sakaran (2006) yang menyatakan bahwa ukuran sampel lebih dari 30 dan kurang dari 500 adalah tepat dan dalam penelitian multivariat termasuk analisis berganda, ukuran sampel sebaiknya beberapa kali (lebih disukai 10 kali atau lebih) lebih besar dari jumlah variabel dalam studi. Dan survei ini dilakukan di 13 Kecamatan di Kabupaten Pohuwato Provinsi Gorontalo. Kuisioner dibagikan sebanyak 300 kepada responden Usaha Mikro dan Kecil dengan asumsi bahwa karakteristik populasi relatif homogen, maka peneliti melakukan penarikan sampel dalam penelitian ini dengan menggunakan teknik acak sederhana (simple random sampling) dengan kriteria: pemilik usaha, sudah berusaha minimal 2 tahun, memiliki jumlah tenaga kerja minimal 1 orang, dan menempati tempat usaha yang permanen.

Dalam penelitian ini kuisioner yang tidak bisa digunakan sebanyak 8 kuesioner disebabkan karena tidak kembali dan jawaban tidak lengkap, sehingga diperoleh 292 responden. Adapun penyebaran kuesioner yang disebar dan yang kembali dapat dilihat pada ringkasan persentase penyebaran sampel yang disajikan pada Tabel 1 berikut. 
Tabel 1. Ringkasan Persentase Penyebaran Sampel UMK di Kabupaten Pohuwato Provinsi Gorontalo

\begin{tabular}{clcccc}
\hline \multirow{2}{*}{ No } & \multirow{2}{*}{ Kecamatan } & \multicolumn{2}{c}{ Kuesioner yang disebar } & \multicolumn{2}{c}{ Kuesioner yang kembali } \\
\cline { 2 - 6 } & & Resp. & $\mathbf{\%}$ & Resp. & \% \\
\hline 1 & Paguat & 28 & 9,33 & 28 & 9,59 \\
\hline 2 & Dengilo & 18 & 6,00 & 18 & 6,16 \\
\hline 3 & Marisa & 40 & 13,33 & 40 & 13,70 \\
\hline 4 & Duhiadaa & 25 & 8,33 & 25 & 8,56 \\
\hline 5 & Buntulia & 31 & 10,33 & 31 & 10,62 \\
\hline 6 & Patilanggio & 27 & 9,00 & 25 & 8,56 \\
\hline 7 & Randangan & 22 & 7,33 & 22 & 7,53 \\
\hline 8 & Taluditi & 17 & 5,67 & 17 & 5,82 \\
\hline 9 & Wonggarasi & 16 & 5,33 & 16 & 5,48 \\
\hline 10 & Lemito & 18 & 6,00 & 18 & 6,16 \\
\hline 11 & Popayato & 21 & 7,00 & 19 & 6,51 \\
\hline 12 & Popayato timur & 17 & 5,67 & 16 & 5,48 \\
\hline 13 & Popayato barat & 20 & 6,67 & 17 & 5,82 \\
\hline & Jumlah & $\mathbf{3 0 0}$ & $\mathbf{1 0 0}$ & $\mathbf{2 9 2}$ & $\mathbf{1 0 0}$ \\
\hline
\end{tabular}

Sumber :Data Primer yang diolah, 2016 dan 2017

Jenis data yang digunakan dalam penelitian ini adalah data kuantitatif. Sedangkan sumber datanya yaitu data primer yang didapatkan secara langsung oleh peneliti berdasarkan hasil penyebaran kuisioner kepada responden yang dijadikan sampel, sedangkan data sekunder diperoleh dari studi kepustakaan, literatur, dan jurnal penelitian terdahulu yang berhubungan dengan permasalahan yang akan diteliti.

Teknik pengumpulan data melalui peninjauan langsung pada lokasi penelitian dengan maksud memperoleh data primer berupa data kuesioner dan informasi penting sebagai tambahan keakurasian data.

Metode analisis yang digunakan dalam penelitian ini yaitu metode statistik regresi berganda dengan menggunakan angka-angka berdasarkan hasil jawaban responden melalui bantuan program SPSS (Statistic Program For Social Science) for windows Versi 20.00.

Adapun bentuk persamaan regresi linear berganda (multiple regression) yang digunakan dalam penelitian ini sebagai berikut :

$$
\mathbf{Y}=\alpha+\boldsymbol{\beta}_{1} \mathbf{X}_{1}+\boldsymbol{\beta}_{2} \mathbf{X}_{2}+\varepsilon
$$

dimana :

$\mathrm{Y}=$ Disiplin pengelolaan keuangan UMK

$\mathrm{X}_{1} \quad=$ Kompetensi pengusaha

$\mathrm{X}_{2}=$ Komitmen keuangan

$\alpha=$ Nilai konstan

$\beta_{1}-\beta_{2}=$ koefisien korelasi

$\varepsilon \quad=$ variabel yang tidak diteliti

Dalam penelitian ini digunakan dua pendekatan pengujuian hipotesis untuk melihat pengaruh variabel independen terhadap variabel dependen, yakni pengujian hipotesis secara parsial dan simultan.

\section{HASIL DAN PEMBAHASAN}

Hasil perhitungan regresi berganda dengan menggunakan program SPSS. Secara ringkas dapat dilihat pada Tabel 2. 
Tabel 2. Ringkasan Hasi Analisis Regresi

\begin{tabular}{|c|c|c|c|c|c|}
\hline \multicolumn{6}{|c|}{ Coefficients $^{\mathrm{a}}$} \\
\hline \multirow[t]{2}{*}{ Model } & \multicolumn{2}{|c|}{$\begin{array}{l}\text { Unstandardized } \\
\text { Coefficients }\end{array}$} & $\begin{array}{c}\text { Standardi } \\
\text { zed } \\
\text { Coefficie } \\
\text { nts } \\
\end{array}$ & \multirow[t]{2}{*}{$\mathrm{t}$} & \multirow[t]{2}{*}{ Sig. } \\
\hline & $\bar{B}$ & $\begin{array}{l}\text { Std. } \\
\text { Error }\end{array}$ & Beta & & \\
\hline \multirow{4}{*}{$1 \frac{\text { (Const) }}{\mathrm{X} 1}$} & 2.744 & .272 & & 10.094 & .000 \\
\hline & .359 & .055 & .350 & 6.549 & .000 \\
\hline & .202 & .050 & .215 & 4.035 & .000 \\
\hline & $\mathrm{nt} \mathrm{Var}$ & ble: Y & & & \\
\hline
\end{tabular}

Sumber : data primer, diolah 2017

Berdasarkan ringkasan hasil regresi seperti yang terlihat pada tabel di atas, maka diperoleh persamaan regresi linear berganda sebagai berikut:

$$
Y=2.744+0.359 X_{1}+0.202 X_{2}
$$

Dari persamaan tersebut, dapat dijelaskan bahwa nilai koefisien regresi kompetensi pengusaha sebesar 0.359 menunjukkan bahwa perubahan variabel kompetensi pengusaha akan diikuti oleh perubahan disiplin pengelolaan keuangan Usaha Mikro dan Kecil sebesar 0.359 dengan asumsi variabel lainnya konstan dan koefisien regresi komitmen keuangan sebesar 0,202 berarti bahwa perubahan variabel komitmen keuangan akan diikuti oleh perubahan disiplin pengelolaan keuangan Usaha Mikro dan Kecil sebesar 0,202 dengan asumsi variabel lainnya konstan. Persamaan regresi di atas juga menunjukkan nilai konstanta sebesar 2,744 yang berarti bahwa nilai disiplin pengelolaan keuangan Usaha Mikro dan Kecil sebesar 2,744 jika variabel lainnya bernilai 0 .

Selanjutnya nilai goodness of fit model yaitu variasi naik turunnya variabel disiplin pengelolaan keuangan Usaha Mikro dan Kecil dapat dilihat melalui nilai koefisien determinasi dengan model summary pada Tabel 3 .
Tabel 3. Ringkasan nilai koefisien determinasi

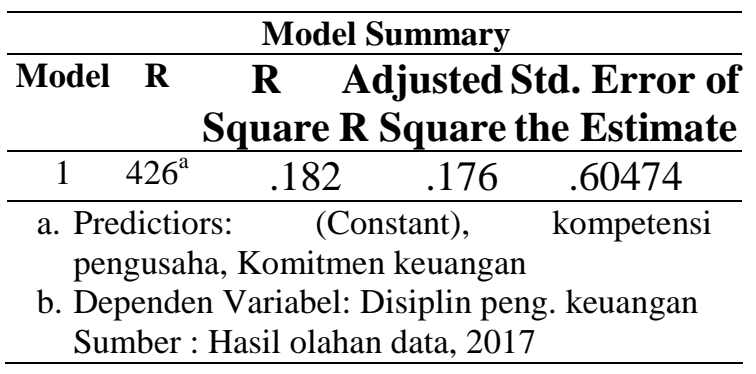

Nilai koefisien determinasi pada tabel di atas menunjukkan angka 0.426 atau $42,60 \%$, artinya bahwa $42,60 \%$ variasi naik turunnya variabel disiplin pengelolaan keuangan Usaha Mikro dan Kecil (Y) mampu dijelaskan oleh variabel kompetensi pengusaha $\left(\mathrm{X}_{1}\right)$ dan komitmen keuangan $\left(\mathrm{X}_{2}\right)$. Sedangkan sisanya sebesar $100-42,60=57,40 \%$ dijelaskan oleh variabel lain diluar model.

Uji-t dilakukan untuk membandingkan nilai $t_{\text {tabel }}$ dan nilai $t_{\text {hitung }}$ pada taraf signifikansi 0,05 . Jika nilai $t_{\text {hitung }}$ lebih besar dari nilai $t_{\text {tabel }} \quad\left(t_{\text {hitung }}>t_{\text {tabel }}\right)$, maka hipotesis penelitian diterima. Sebaliknya jika nilai $t_{\text {hitung }}$ lebih kecil dari nilai $t_{\text {tabel }}$ ( $\left.t_{\text {hitung }}<t_{\text {tabel }}\right)$, maka hipotesis penelitian ditolak. Adapun nilai $t_{\text {tabel }}$ untuk $\alpha=5 \%$, dan nilai df sebesar $\mathrm{n}-\mathrm{k}-1=$ $292-2-1=289$, maka nilai df adalah 289, sedangkan nilai t-tabel diperoleh sebesar 1,968. Dan Uji signifikansi juga dapat dilihat dari nilai signifikansi koefisien regresi. Jika nilai signifikaansi lebih kecil dari 0,05 maka hipotesis penelitian dapat diterima. Sebaliknya jika nilai signifikansi lebih besar dari 0,05 maka hipotesis penelitian ditolak.

\section{Pengujian Hipotesis Pertama $\left(\mathbf{H}_{1}\right)$}

Pengaruh kompetensi pengusaha terhadap disiplin pengelolaan keuangan Usaha Mikro dan Kecil dispesifikasikan dalam hipotesis pertama $\left(\mathrm{H}_{1}\right)$ yaitu: 
$\mathrm{H}_{1}$ : Kompetensi pengusaha berpengaruh signifikan terhadap disiplin pengelolaan keuangan Usaha Mikro dan Kecil.

Berdasarkan perhitungan analisis regresi diperoleh $t_{\text {hitung }}$ sebesar 5,256. Nilai ini lebih besar dari $t_{\text {tabel }}$ sebesar 1.968, yang berarti bahwa secara signifikan kompetensi pengusaha berpengaruh terhadap disiplin pengelolaan keuangan Usaha Mikro dan Kecil. Hal ini juga didukung dengan nilai signifikansi sebesar 0,000. Dengan demikian dapat dikatakan bahwa hipotesis penelitian yang menyatakan kompetensi pengusaha berpengaruh signifikan terhadap disiplin pengelolaan keuangan Usaha Mikro dan Kecil diterima.

\section{Pengujian Hipotesis Kedua $\left(\mathrm{H}_{2}\right)$}

Pengaruh komitmen keuangan terhadap disiplin pengelolaan keuangan Usaha Mikro dan Kecil dispesifikasikan dalam hipotesis kedua $\left(\mathrm{H}_{2}\right)$ yaitu:

$\mathrm{H}_{2}$ : Komitmen keuangan berpengaruh signifikan terhadap disiplin pengelolaan keuangan Usaha Mikro dan Kecil.

Berdasarkan perhitungan analisis regresi diperoleh $t_{\text {hitung }}$ sebesar 4.308. Nilai ini lebih besar dari $t_{\text {tabel }}$, sebesar 1,968 yang berarti bahwa secara signifikan komitmen keuangan berpengaruh terhadap disiplin pengelolaan keuangan Usaha Mikro dan Kecil. hal ini juga didukung dengan nilai signifikansi sebesar 0,000. Dengan demikian dapat dikatakan bahwa hipotesis penelitian yang menyatakan komitmen keuangan berpengaruh signifikan terhadap disiplin pengelolaan keuangan Usaha Mikro dan Kecil diterima.

Uji-F atau ANOVA digunakan untuk membandingkan tingkat signifikansi dengan (probability value) yang ditetapkan untuk penelitian ini dengan probability value hasil penelitian. Hasil regresi dari Uji-F dapat dilihat pada Tabel 4.

Tabel 4. Hasil regresi Uji-F

\begin{tabular}{|c|c|c|c|c|c|c|}
\hline \multicolumn{7}{|c|}{ ANOVA $^{a}$} \\
\hline \multicolumn{2}{|c|}{ Model } & Sum of & Df & Mean & $\mathrm{F}$ & Sig. \\
\hline \multirow[t]{3}{*}{1} & Reg & 23.480 & 2 & 11.740 & 32.102 & $.000^{\mathrm{b}}$ \\
\hline & Res & 105.690 & 289 & .366 & & \\
\hline & Total & 129.170 & 291 & & & \\
\hline
\end{tabular}

a. Dependen Variable : Disiplin pengelolaan keuangan

b. Predictors : (Constant), kompetensi pengusah, komitmen keuangan

Sumber : Hasil olahan data, 2017

Pengujian terhadap hipotesis ketiga yaitu pengaruh variabel indepeden terhadap variabel dependen secara simultan menggunakan uji F.

$\mathrm{H}_{3}$ : Kompetensi pengusaha dan komitmen keuangan secara simultan berpengaruh signifikan terhadap disiplin pengelolaan keuangan Usaha Mikro dan Kecil.

Berdasarkan perhitungan regresi linear berganda pada tabel di atas, nampak bahwa nilai $F_{\text {hitung }}$ lebih besar dari nilai $\mathrm{F}_{\text {tabel }}(32,102>3,027)$ dengan probabilitas terjadinya kesalahan $\mathrm{F}_{\text {hitung }}$ lebih kecil dari taraf kesalahan $(\alpha)$ yang ditetapkan yaitu $0,000<0,05$.

Hasil penelitian membuktikan bahwa variabel independen yang terdiri dari kompetensi pengusaha $\left.\left(\mathrm{X}_{1}\right)\right)$ dan komitmen keuangan $\left(\mathrm{X}_{2}\right)$ secara simultan berpengaruh terhadap disiplin pengelolaan keuangan Usaha Mikro dan Kecil (Y) di Kabupaten Pohuwato Provinsi Gorontalo.

Pembahasan pada penelitian ini akan menjawab masalah yang dirumuskan berdasarkan hasil analisis deskriptif dan analisis regresi linier berganda dengan menggunakan bantuan SPSS versi 20.00.

Berdasarkan hasil analisis regresi linier berganda yang tampak pada Tabel 
4.1, maka Ho yang berbunyi "tidak ada pengaruh antara kompetensi pengusaha secara parsial terhadap disiplin pengelolaan keuangan Usaha Mikro dan Kecil di Kabupaten Pohuwato Provinsi Gorontalo" ditolak. Sedangkan $\mathrm{H}_{1}$ yang berbunyi "ada pengaruh kompetensi pengusaha secara parsial terhadap disiplin pengelolaan keuangan Usaha Mikro dan Kecil di Kabupaten Pohuwato Provinsi Gorontalo" diterima.

Hasil penelitian ini memperkuat hasil penelitian terdahulu yang dilakukan oleh Rakhman (2011), di mana temuannya menunjukkan bahwa kemampuan pengusaha telah efektif dengan disiplin keuangan. Hasil penelitian ini juga memperkuat hasil penelitian oleh Akola, E., Heinonen, J. (2006), ditemukan bahwa pembelajaran yang dibuat dalam proses percobaan kepada pengusaha dan berpengaruh positif dalam situasi pengetahuan kehidupan nyata dan pengalaman yang diperoleh.

Hasil penelitian ini juga sejalan dengan hasil penenlitian Sarwoko, dkk, (2013), Hasil penelitiannya menunjukkan bahwa karakteristik kewirausahaan memiliki pengaruh yang signifikan terhadap kinerja bisnis. Kompetensi kewirausahaan sebagai mediasi dalam hubungan antara karakteristik kewirausahaan dan kinerja bisnis.

Secara teori, penelitian ini mendukung pendapat Herron dan Robinson yang menyatakan bahwa pengalaman pengusaha, pelatihan, pendidikan, latar belakang keluarga dan variabel demografis lainnya dianggap sebagai faktor yang mempengaruhi kompetensi kewirausahaan.

Berdasarkan hasil ringkasan analisis regresi linier berganda yang tampak pada Tabel 4.1 maka Ho yang berbunyi "tidak ada pengaruh antara komitmen keuangan secara parsial terhadap disiplin pengelolaan keuangan Usaha Mikro dan Kecil di Kabupaten Pohuwato Provinsi Gorontalo" ditolak. Sedangkan $\mathrm{H}_{2}$ yang berbunyi "ada pengaruh komitmen keuangan secara parsial terhadap disiplin pengelolaan keuangan Usaha Mikro dan Kecil di Kabupaten Pohuwato Provinsi Gorontalo" diterima.

Dari hasil penelitian ini sejalan dengan hasil penelitian yang dilakukan oleh Alam (2005), di mana hasil penelitiannya menemukan bahwa variabel aspek keuangan, aspek lingkungan, aspek pemasaran, aspek sumberdaya manusia dan aspek kewirausahaan secara parsial maupun secara simultan berpengaruh secara signifikan terhadap kinerja usaha sektor informal di Sulawesi Selatan.

Hasill penelitian ini juga mendukung pendapat Andreas dan Anna yang mengungkapkan bahwa berhasil tidaknya perusahaan mencapai tujuan dan pertumbuhan secara berkelanjutan sangat tergantung pada komitmen pada perusahaan, selalu bertindak dengan mengelola biaya secara efektif dalam setiap aktivitasnya, dan melakukan tindakan yang selaras antara tujuan pribadi dan tujuan perusahaan (congruence of goals).

Berdasarkan hasil analisis regresi linier berganda yang tampak pada Tabel 4.1, menunjukkan bahwa variabel kompetensi pengusaha dan komitmen keuangan mempunyai pengaruh yang signifikan terhadap disiplin pengelolaan keuangan Usaha Mikro dan Kecil di Kabupaten Pohuwato Provinsi Gorontalo. Hal tersebut ditunjukkan oleh nilai $F_{\text {hitung }}$ diperoleh sebesar 32,102. Nilai $F_{\text {tabel }}$ yaitu sebesar 3,027 yang diperoleh dari tabel $\mathrm{F}$, dengan ketentuan df $1=2$ atau jumlah variabel-1 (3-1), sementara df $2=292$ atau n-k-1 (292-2-1) dengan tingkat signifikansi 5\%. Karena Fhitung $(32,102)$ $>$ Ftabel $(3,027)$ maka menerima Ha. 
Selain itu diperoleh nilai signifikansi (sig. $=0,000)$ yang lebih kecil dari pada $\alpha=$ 0.05 yang disyaratkan. Karena sig $0,00<$ 0.05 yang berarti menerima Ha. Artinya kompetensi pengusaha dan komitmen keuangan secara simultan berpengaruh signifikan terhadap disiplin pengelolaan keuangan Usaha Mikro dan Kecil di Kabupaten Pohuwato Provinsi Gorontalo.

Dari hasil tersebut di atas dapat disimpulkan bahwa Ho yang berbunyi "tidak ada pengaruh antara kompetensi pengusaha dan komitmen keuangan secara simultan terhadap disiplin pengelolaan keuangan Usaha Mikro dan Kecil di Kabupaten Pohuwato Provinsi Gorontalo" ditolak. Sedangkan $\mathrm{H}_{3}$ yang berbunyi "ada pengaruh kompetensi pengusaha dan komitmen keuangan secara simultan berpengaruh terhadap disiplin pengelolaan keuangan Usaha Mikro dan Kecil di Kabupaten Pohuwato Provinsi Gorontalo" diterima.

\section{PENUTUP}

\section{Kesimpulan}

Berdasarkan hasil penelitian dan pembahasan yang telah dikemukakan sebelumnya, maka selanjutnya dapat ditarik beberapa simpulan sebagai berikut:

1. Kompetensi pengusaha dan komitmen keuangan secara parsial mempunyai pengaruh yang signifikan terhadap disiplin pengelolaan keuangan Usaha Mikro dan Kecil di Kabupaten Pohuwato Provinsi Gorontalo..

2. Secara simultan variabel kompetensi pengusaha dan komitmen keuangan mempunyai pengaruh yang signifikan terhadap disiplin pengelolaan keuangan Usaha Mikro dan Kecil di Kabupaten Pohuwato Provinsi Gorontalo.
DAFTAR PUSTAKA

Alam Syamsu. (2005). 'Factors Affecting Informal Sector Performances in South Sulawesi (Cases Makassar. Parepare and Watanpone Regencies)'. Unpublished Dissertation. Hasanuddin University Makassar.

Alma Buchari. (2013). Kewirausahaan untuk Mahasiswa dan Umum. Cetakan ke-18. Penerbit Alfabeta. Bandung

BPS Kabupaten Pouwato. 2015/2016: Kabupaten Pohuwato Dalam Angka.

Coleman. Susan. (2007). 'The Role of Human and Financial Capital in the Profitability and Growth of Women-Owned Small Firms'. Journal of Small Business Management. 45(3) pp.303-319.

Indriani. Irene dan Supramono. (2009). Pengaruh Personality Traits Terhadap Penyalahgunaan Kartu Kredit Dengan Impulsiveness Sebagai Variabel Intervening: Studi Pada Pegawai Akademik \& Non Akademik YPTKSW. Riset. FE UKSW. Salatiga.

Raduan. (2006). The dynamics of entrepreneurs' success factors in influencing venture growth. Journal of Asia Entrepreneurship and Sustainability. Volume II. Issue 3.

Rakhman Abdul. (2011). Financial Discipline: A Survey Of Entrepreneurs' Perspectives In South Sulawesi. Journal Of Economics. Business And Accountancy Ventura Volume 14. 
No. 2. August 2011. Pages 119 132

Sanchez Jose. (2011). The influence of entrepreneurial competencies on small firm performance. Revista Latinoamericana de Psicología. vol. 44. núm. 2. 2012. pp. 165-177 Fundación Universitaria Konrad Lorenz Bogotá. Colombia.

Sarwoko Endi. dkk. (2013). Entrepreneurial Characteristics and Competency as Determinants of Business Performance in SMEs (Economics and Business Faculty. University of Brawijaya. Indonesia). IOSR Journal of Business and Management (IOSRJBM) e-ISSN: 2278-487X. Volume 7. Issue 3 (Jan. - Feb. 2013). PP 31-38.

Sakaran Uma. (2006). "Research Methods For Business (Metodologi Penetian untuk Bisnis)'”. Edisi 4. Penerbit Salemba Empat. Jakarta.

Senduk. Safir. (2000). Mengelola Keuangan Keluarga. Seri Perencanaan Keuangan Keluarga. Elex Media Komputindo. Jakarta.

Suryana. (2013). Kewirausahaan. Pedoman Praktis. Kiat. dan Proses Menuju Sukses. Salemba Empat. Jakarta.

Suswardji Edi. dkk. (2012). Hubungan Kompetensi dan Disiplin Kerja Terhadap Kinerja Tenaga Kependidikan Universitas Singaperbangsa Karawang. Jurnal Manajemen Vol. 1. No. 1 Oktober 2012 